\title{
Cynomolgus Monkey
}

National Cancer Institute

\section{Source}

National Cancer Institute. Cynomolgus Monkey. NCI Thesaurus. Code C14232.

A macaque, Macaca fascicularis (M. cynomolgus), found mostly in southeastern Asia, Borneo, and the Philippines. 